\title{
The Miscibility of Homopolymer/Random Copolymer Blends IV. Poly(vinylidene chloride-co-acrylonitrile)/Poly(methyl methacrylate) Blends
}

\author{
Hanqiao Feng, ${ }^{\dagger}$ Chaohui Ye, and Zhiliu FenG* \\ Laboratory of Magnetic Resonance and Atomic and Molecular Physics, \\ Wuhan Institute of Physics, Chinese Academy of Sciences, \\ Wuhan 430071, People's Republic of China \\ * Polymer Physics Laboratory, Changchun Institute of Applied Chemistry, \\ Chinese Academy of Sciences, Changchun 130022, \\ People's Republic of China
}

(Received December 25, 1995)

\begin{abstract}
The miscibility of blends of poly(vinylidene chloride-co-acrylonitrile) (VDC-AN) and poly(methyl methacrylate) (PMMA) has been studied with DSC, FT-IR, and NMR methods. The results indicate that the VDC-AN/PMMA blends are miscibile on a molecular level, and the dipole-dipole interactions between $\mathrm{C}=\mathrm{O}$ and $\mathrm{C}-\mathrm{Cl} \mathrm{l}_{2}$ and/or interpolymer hydrogen bondings between $\mathrm{COOCH}_{3}$ and $\mathrm{CN}$ and $\mathrm{CCl}$ groups play the role on the miscibility of the blends. It is found that the $-\mathrm{CCl}_{2}-$ groups have two different chemical environments in the pure VDC-AN copolymer, which may result from the different configurations of the copolymer, such as $-\mathrm{CCl}_{2}-$ groups in the "alternating" segments and $-\mathrm{CCl}_{2}-\mathrm{groups}$ in the "blocky" segments as proposed. It is the $-\mathrm{CCl}_{2}$ - group in the "alternating" segment that takes part in the dipole-dipole interaction with $\mathrm{C}=\mathrm{O}$ group in PMMA.

KEY WORDS ${ }^{13} \mathrm{C}$ Cross Polarization Magic Angle Spinning Nuclear Magnetic Resonance $\left({ }^{13} \mathrm{C} \mathrm{CPMAS}\right.$

NMR) / Fourier-Transfer-Infrared Spectroscopy (FT-IR) / Differential Scanning Calorimetry (DSC) /

Dipole-Dipole Interaction / Random Copolymer /
\end{abstract}

This is the fourth part of a series of studies on the miscibility of blends of a homopolymer with a random copolymer. In the preceding papers, ${ }^{1-3}$ the miscibility of the blends of PS-based copolymer, poly(styrene-coacrylonitrile) (SAN), poly(styrene-co-maleic anhydride) (SMA), and poly(styrene-co-allyl alcohol) (SAA), with poly(methyl methacrylate) (PMMA), and with other homopolymers were investigated in detail with a variety of physical methods. A very important experimental evidence obtained is that there is a strong intermolecular interaction between the phenyl group in PS-based copolymers and the carbonyl group in polymathacrylates or polyesters. And the strength of the interaction to some degree depends on the physical properties of the ester (side) group of the homopolymers studied, which plays an important role in the miscibility of the homopolymer and random copolymer blends. In this work, the miscibility of blends comprising of poly(vinylidene-coacrylonitrile) (VDC-AN) and PMMA was studied with DSC, FT-IR, and NMR methods. VDC-AN was chosen as a candidate in order to see the difference between the miscibility of VDC-AN/PMMA and that of SAN/ PMMA, which should be resulted from the only difference between the comonomers of the AN copolymers, i.e., one is styrene and the other is vinylidene chloride. Some interesting results are obtained.

\section{EXPERIMENTAL}

The polymers, VDC-AN $(80: 20)$ and PMMA $\left(\eta_{1}=\right.$ $0.4)$, used in this study were purchased from Polyscience, Inc., U.S.A. Solution blending with tetrahydrofuran (THF) as solvent was used, and solution concentration is $10 \%(\mathrm{w} / \mathrm{v})$. Specimens with different compositions

\footnotetext{
$\dagger$ To whom correspondence should be addressed.
}

were cast from the solution at room temperature, and then dried under vacuum at $80^{\circ} \mathrm{C}$ for a week.

Solid state ${ }^{13} \mathrm{C}$ CPMAS NMR experiments were performed on a BRUKER MSL-400 NMR spectrometer at $298.0 \mathrm{~K}$. TOSS method was used for suppressing spinning side bands. The proton resonance frequency was $400.13 \mathrm{MHz}$, and carbon resonance frequency was $100.63 \mathrm{MHz}$, while $5.5 \mu \mathrm{s} 90^{\circ}$ pulse for ${ }^{13} \mathrm{C}$ nucleus and $4.8 \mu \mathrm{s} 90^{\circ}$ pulse for ${ }^{1} \mathrm{H}$ were used. Magic-angle spinning rate was $4000 \mathrm{kHz} .{ }^{13} \mathrm{C}$ spin-lattice relaxation times were measured by the $T_{1} \mathrm{CP}$ method, ${ }^{4}$ and ${ }^{1} \mathrm{H}$ spin-lattice relaxation time in the rotating frame, $T_{1 \rho}(\mathrm{H})$, were obtained from the ${ }^{13} \mathrm{C}$ CPMAS intensity with increasing contact times. ${ }^{513} \mathrm{C}$ spectra were referred to the chemical shift of methyl group carbons of hexamethylbenzene, which is $16.9 \mathrm{ppm}$.

FT-IR experiments were carried out with a FTS-20E spectrometer. Measurements were taken at $4 \mathrm{~cm}^{-1}$ resolution.

DSC curves of the specimens were recorded at a heating rate of $10 \mathrm{~K} \mathrm{~min}^{-1}$ with a Perkin-Elmer DSC-2 apparatus. The temperature at the midpoint of the heat capacity of the DSC curve was taken as $T_{\mathrm{g}}$ of the specimen.

\section{RESULTS AND DISCUSSION}

\section{Glass Transition Behavior}

A single, composition dependent $T_{\mathrm{g}}$ is generally accepted as a criterion for blend miscibility. As shown in Figure 1, there appears only one $T_{\mathrm{g}}$ transition on each DSC curve, hence the VDC-AN/PMMA blends studied are miscible. The dependence of their $T_{\mathrm{g}}$ 's on composition is similar to that of SMA/PMMA blends, ${ }^{2}$ i.e., the $T_{\mathrm{g}}$ 's of the blends all lie above the straight line connecting the $T_{\mathrm{g}}$ 's of the pure components and are much higher 


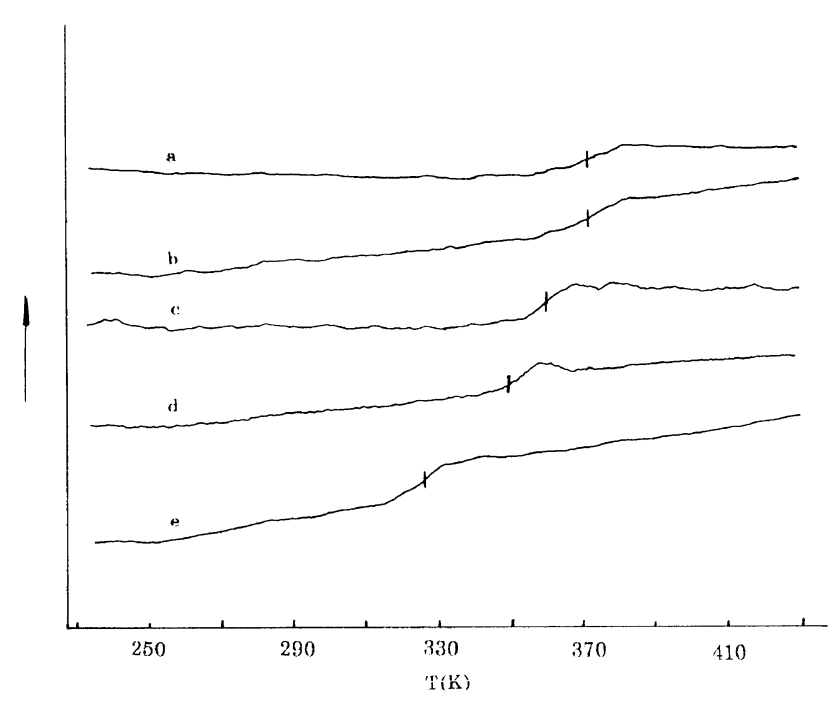

Figure 1. DSC curves of the VDC-AN/PMMA blends of different compositions. VDC-AN/PMMA: a) $0: 100$; b) $25: 75$; c) $50: 50$; d) $75: 25$; e) $100: 0$.

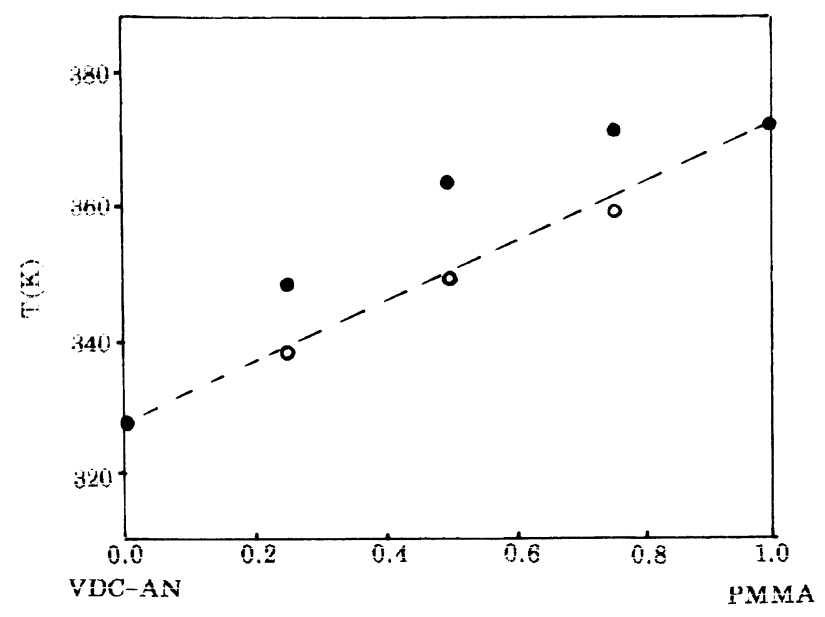

Figure 2. The glass transition temperatures of VDC-AN/PMMA blends vs. blend composition: $(\bigcirc)$ the values calculated with Fox equation; (O) experimental values.

than the $T_{\mathrm{g}}$ values calculated from the Fox equation (Figure 2). ${ }^{6}$ Hence, the interactions between the blend components in these systems are sufficiently strong as they cause positive diviations from the linear relationship. ${ }^{7,8}$ This proposition is supported by both our NMR and FT-IR results.

\section{NMR Results}

The CPMAS ${ }^{13} \mathrm{C}$ NMR spectra of the VDCAN/PMMA blends are shown in Figure 3. The resonance assignments of VDC-AN carbons are marked on the corresponding peaks of the spectrum of Figure 3(e). There are two very important points that need to be mentioned. First, copolymerization has a rather strong effect on the electron density of the methylenic carbon in AN monomer because its chemical shift moves towards the lower field about $30 \mathrm{ppm}$ as compared with that in homopolymer polyacrylonitrile. There is no doubt that it is the induction effect of the neighboring chlorine atoms, which cause such a big lower-field shift. Secondly, it is seen that the $-\mathrm{CCl}_{2}-$ carbon resonance in pure VDC-AN copolymer (peak C2, Figure 3(e)) is not sharp and not symmetric, but with a shoulder, in-

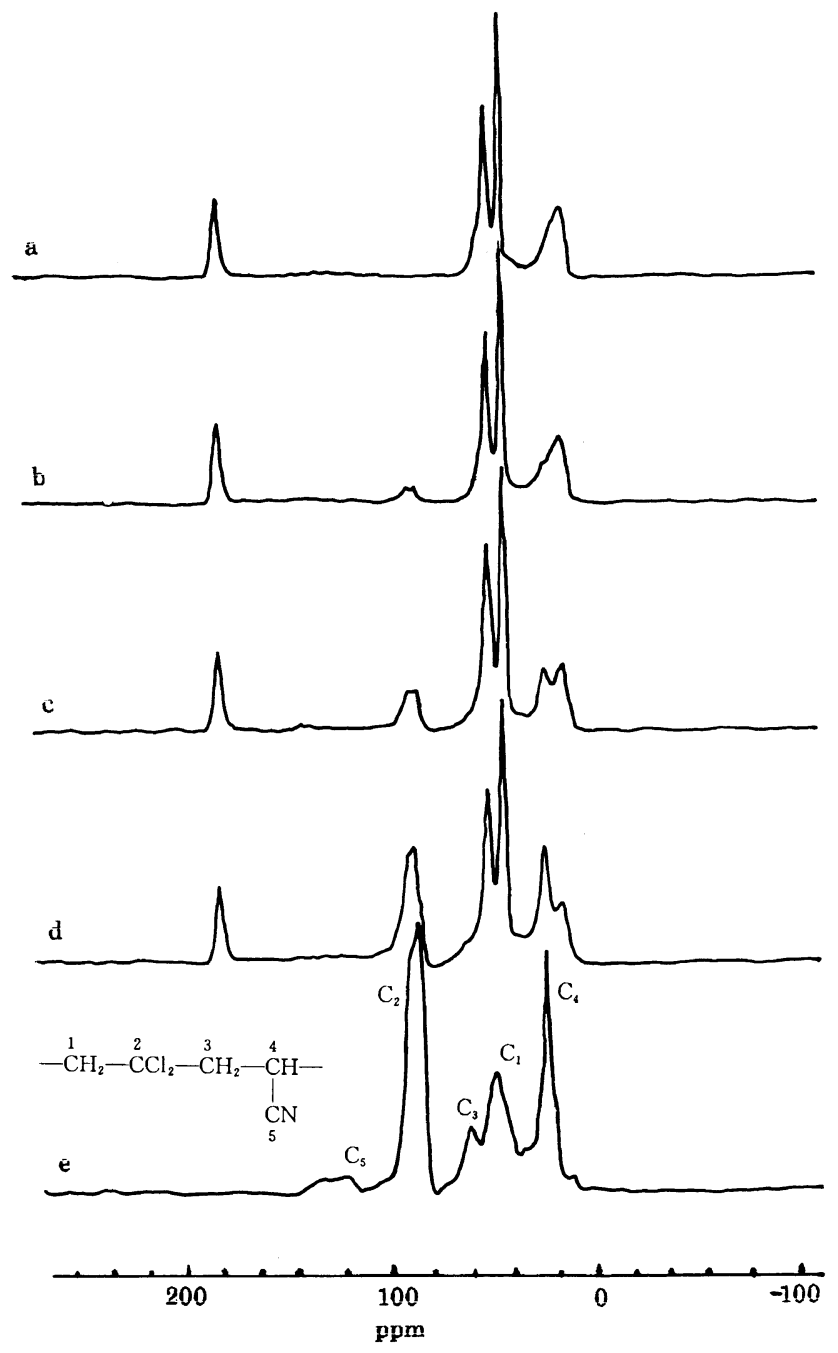

Figure 3. ${ }^{13} \mathrm{C}$ CPMAS NMR spectra VDC-AN, PMMA and their blends. VDC-AN/PMMA: a) $0: 100$; b) $25: 75$; c) $50: 50$; d) $75: 25$; e) $100: 0$.

Table I. Chemical shifts of $\mathrm{C}=\mathrm{O},-\mathrm{CCl}_{2^{-}}$, and $-\mathrm{CH}_{3}-$ groups in VDC-AN/PMMA blends

\begin{tabular}{cccc}
\hline \multirow{2}{*}{$\begin{array}{c}\text { Composition } \\
\text { VDC-AN/PMMA }\end{array}$} & \multicolumn{3}{c}{${ }^{13} \mathrm{C}$ Chemical shift/ppm } \\
\cline { 2 - 4 } & $-\mathrm{CCl}_{2}-$ & $\mathrm{C}=\mathrm{O}$ & $-\mathrm{CH}_{3}$ \\
\hline $100: 0$ & 85.7 & - & - \\
$75: 25$ & 87.2 & 177.9 & 18.0 \\
$50: 50$ & 87.9 & 177.8 & 17.8 \\
$25: 75$ & $89.2,86.5$ & 177.7 & 17.3 \\
$0: 100$ & - & 177.5 & 17.3 \\
\hline
\end{tabular}

dicating that the $-\mathrm{CCl}_{2}-$ carbons have different chemical environments, which could be the result of two possible factors. One is the configuration of the copolymer. For instance, the chemical environment of a "blocky" VDC segment will be very different from that of an "alternating" VDC-AN segment, even in the "alternating" segments, the chemical environments of head-head configuration will be different from that of head-tailer configuration. The other is that the inter- and intramolecular interactions in pure VDC-AN copolymer are very complicated. However, it is considered that the first point may be the predominant one.

From Figure 3 and Table I, it is clearly seen that mixing PMMA with VDC-AN will result in some changes of 


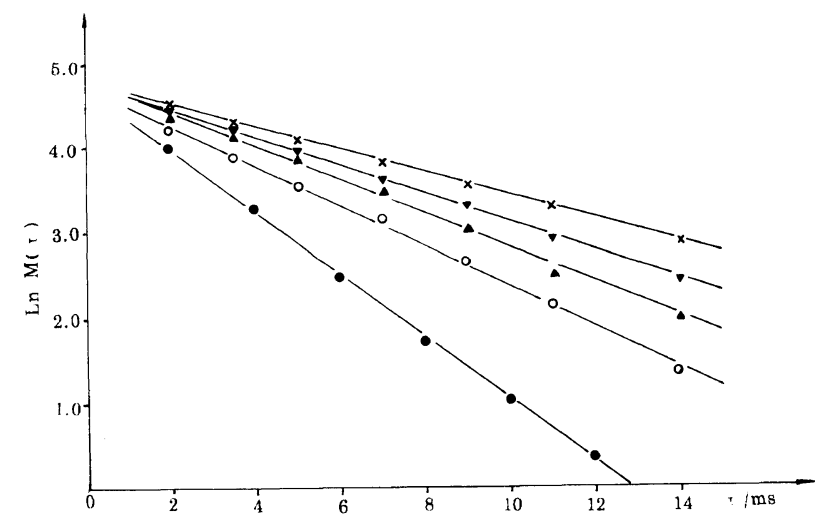

Figure 4. Plots of the logarithmic ${ }^{13} \mathrm{C}$ CPMAS resonance intensity vs. time of proton spin-locking of VDC-AN/PMMA: (○) 100:0; (O)

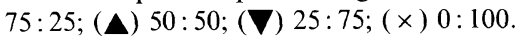

Table II. $T_{1 \rho}(\mathrm{H})^{\mathrm{a}}$ values of VDC-AN, PMMA, and their blends

\begin{tabular}{cc}
\hline VDC-AN/PMMA & $T_{1 \rho}(\mathrm{H}) / \mathrm{ms}$ \\
\hline $100: 0$ & 8.0 \\
$75: 25$ & 8.6 \\
$50: 50$ & 9.7 \\
$25: 75$ & 12.0 \\
$0: 100$ & 13.4 \\
\hline
\end{tabular}

${ }^{a}$ Estimated error $\leq+5 \%$.

chemical shifts and line shape of both the polymers. Among them, change of the $-\mathrm{CCl}_{2}-$ carbon peak is the most. With increase in PMMA content, the lower-field shift of the $-\mathrm{CCl}_{2}-$ carbon increases and the line-shape of the $-\mathrm{CCl}_{2}-$ peak changes. When the PMMA content is high up to $75 \mathrm{wt} \%$, the $-\mathrm{CCl}_{2}$ - peak changes from asymmetric to symmetric splitted peak with $3 \mathrm{ppm}$ apart, implying that the $-\mathrm{CCl}_{2}-$ group is involved in the intermolecular interactions between VDC-AN and PMMA. Besides, the carbonyl and methine group are also involved in such interactions. NMR results can not tell whether or not the $\mathrm{CN}$ and methylene groups in VDC-AN are involved in the interactions due to their poor intensity and overlapping. However, the results mentioned above are enough to indicate that VDC-ANPMMA blends are miscible on a molecular level, which is the result of the intermolecular interactions discussed above. This conclusion is further supported by the results of the proton spin-lattice relaxation times, $T_{1 \rho}(\mathrm{H})$, of the blends in the rotating frame (Figure 4 and Table II) due to the existence of a single $T_{1 \rho}(\mathrm{H})$ value for all the blends.

\section{FT-IR Results}

The IR spectra of the blends (Figures 5, 6, and Table III) give us many interesting information. A very surprising one is the appearance of a new band at $1778 \mathrm{~cm}^{-1}$ on the IR spectra of the blends, since there is no such a band for either of the pure polymers or the solvent THF used for blending, and that the position of this new band does not depend on the composition of the blends, but its relative intensity decreases with the increase in the content of PMMA. A possible explanation for this new peak is that some chemical reaction occurs in the VDC-AN/PMMA blends. But the site for the reaction is still in question. On the other hand, the $\mathrm{C}-\mathrm{Cl}$ stretching 680

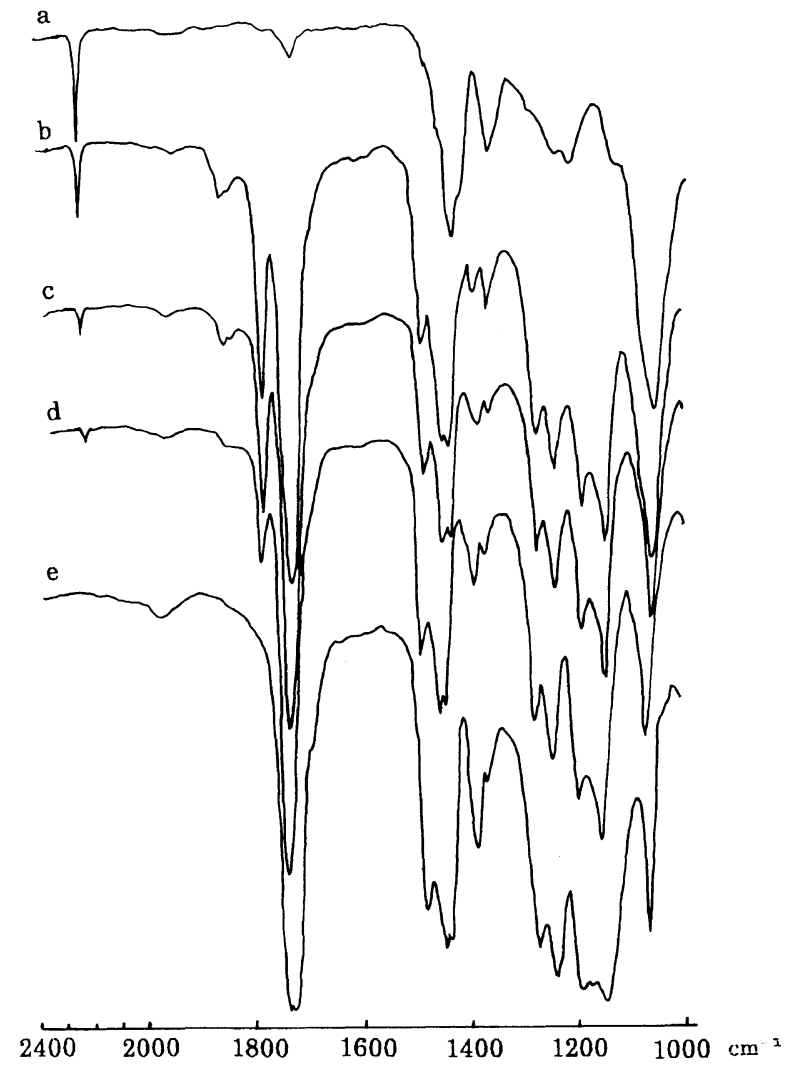

Figure 5. FT-IR spectra (region $100-2400 \mathrm{~cm}^{-1}$ ) of the blends with VDC-AN/PMMA: a) $100: 0$; b) $75: 25$; c) $50: 50$;) $25: 75$; e) $0: 100$.

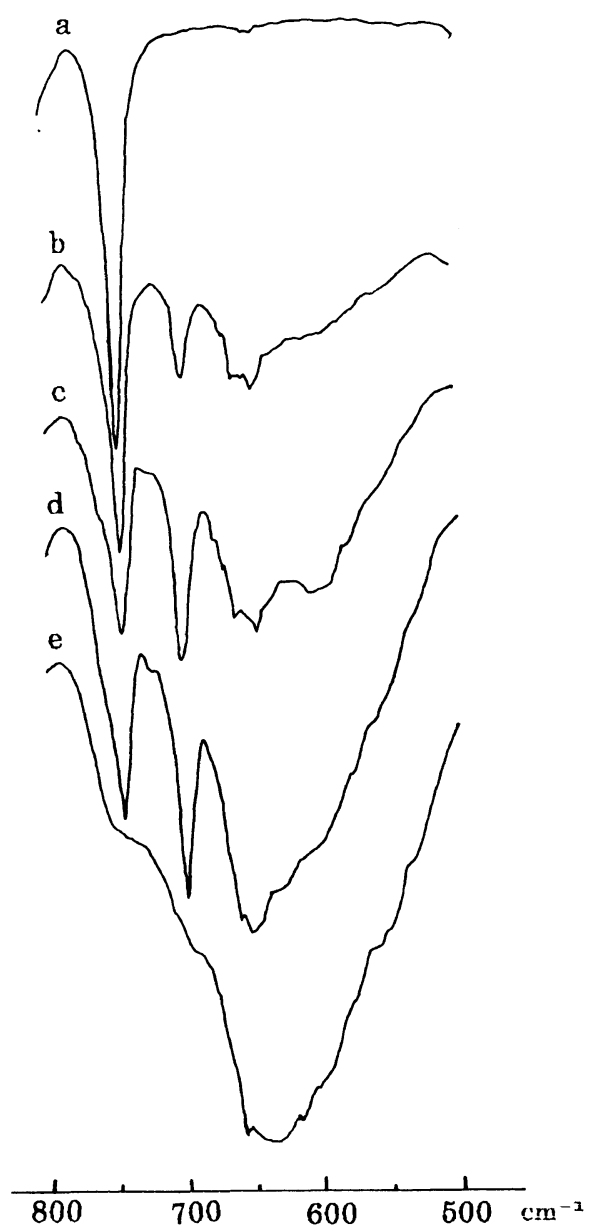

Figure 6. FT-IR spectra (region $500-800 \mathrm{~cm}^{-1}$ ) of the blends with VDC-AN/PMMA: a) $0: 100$; b) $25: 75$; c) $50: 50$; d) $75: 25$; e) $100: 0$.

Polym. J., Vol. 28, No. 8, 1996 
Table III. Wavenumbers of the $\mathrm{C}=\mathrm{N}, \mathrm{C}=\mathrm{O}, \mathrm{C}-\mathrm{Cl}$ and $-\mathrm{C}-\mathrm{O}-\mathrm{C}-$ groups in VDC-AN/PMMA blends

\begin{tabular}{ccccc}
\hline & \multicolumn{5}{c}{ Wavenumber/cm ${ }^{-1}$} \\
VDC-AN/PMMA & $v(\mathrm{C}=\mathrm{N})$ & $v(\mathrm{C}=\mathrm{O})$ & $v(\mathrm{C}-\mathrm{Cl})$ & $v(-\mathrm{C}-\mathrm{O}-\mathrm{C})$ \\
\cline { 2 - 5 } & 2219 & - & 620,640 & - \\
$100: 0$ & 2218 & 1729 & $700,662,653$ & 1239,1272 \\
$75: 25$ & 2217 & 1729 & $700,662,645,605$ & 1237,1270 \\
$50: 50$ & 2216 & 1730 & $699,663,648$ & 1237,1270 \\
$25: 75$ & - & 1735 & - & 1237,1270 \\
$0: 100$ & & & &
\end{tabular}

vibrations in the IR spectra of the blends are greatly changed by the addition of PMMA, which is in agreement with the results obtained by NMR. As reported, homopolymer/poly(vinylidene chloride) (PVDC) has four $\mathrm{C}-\mathrm{Cl}$ stretching frequencies, being at 530, 602, 658, and $688 \mathrm{~cm}^{-1}$, respectively. ${ }^{9}$ However, in copolymer VDC-AN, there is only one very broad peak at the corresponding region for $\mathrm{C}-\mathrm{Cl}$ stretching vibration (Figure 6(e)), indicating the existence of very complicated chemical environments for $\mathrm{C}-\mathrm{Cl}$ in pure VDC-AN copolymer. When PMMA was mixed with VDC-AN, the broad $\mathrm{C}-\mathrm{Cl}$ vibration peak splits into two kinds of peaks, one is well-defined at $700 \mathrm{~cm}^{-1}$, the other is still a broad one comprising of several ill-defined peaks. With the increase in PMMA content, the position of the well-defined peak is almost not changed, the broad one tends to split, the peak intensities depend on the PMMA content. It is interesting to notice that the situation is similar to that of the NMR spectra of the same blends. As discussed in the previous section, our NMR results have shown that the $-\mathrm{CCl}_{2}-$ resonance peak is also composed of two ill-defined peaks, and with the increase in the PMMA content, the $-\mathrm{CCl}_{2}$ - peak is splitted into two well-defined peaks. From the change of the NMR peaks it is seen that the higher-field $-\mathrm{CCl}_{2}-$ peak changes with the addition of PMMA, and the lower-field $-\mathrm{CCl}_{2}-$ peak does not. Therefore, it may be considered that there are at least two kinds of $-\mathrm{CCl}_{2}-$ groups with rather different chemical environments in pure VDC-AN copolymer, one is involved in the intermolecular interactions between VDC-AN and PMMA, and the other not. As far as configuration is concerned, it is suggested that the former may be assigned to the $-\mathrm{CCl}_{2}-$ groups as "alternating" segments, and the latter may be assigned to the $-\mathrm{CCl}_{2}-$ groups as "blocky" segments. Hence, it may be seen that the sequence distribution of a copolymer is very important for the miscibility of homopolymer/copolymer blends. However, this suggestion should be further confirmed experimently.

The next thing needs to be done is the determination of what kinds of intermolecular interactions existing in the blends. The miscibility of VDC-AN/PCL blends was studied with FT-IR by Coleman et al. ${ }^{10}$ Their conclusion is that VDC-AN is miscible with PCL in amorphous state, which is due to the strong intermolecular interactions existing between the carbonyl groups in PCL and the VDC-AN copolymer. But they could not tell precisely what kind of interaction involved in the miscibility of the VDC-AN/PCL blends because they did not try to see whether there was any change of the IR spectra of the blends, which will suggest how the $\mathrm{C}-\mathrm{Cl}$ or $\mathrm{C}=\mathrm{N}$ groups are involved in any interaction. Of course, as they pointed out, this does not exclude the possibility that such an interaction could exist and was not detected by IR spectroscopy because of lack of sensitivity or of low concentration effect.

However, our NMR and FT-IR results indicate that the $\mathrm{C}=\mathrm{O}, \mathrm{C}-\mathrm{Cl}$, and the methine groups are involved in the intermolecular interactions between PMMA and VDC-AN. At the same time, a lower frequency shift of the $\mathrm{CN}$ stretching vibration was also observed in the VDC-AN/PMMA blends. Therefore, there are possibly several kinds of intermolecular interactions between PMMA and VDC-AN, such as those between carbonyl groups and $\mathrm{CCl}$ or $\mathrm{CN}$ groups, between carbonyl groups and methylene or methine groups ( $\alpha$-proton or $\beta$-protons) in VDC-AN. According to our NMR and FT-IR results, it is suggested that probably dipole-dipole interaction between the carbonyl groups of PMMA and $\mathrm{C}-\mathrm{Cl}$ groups of the VDC-AN and/or interpolymer hydrogen bondings between $\mathrm{COOCH}_{3}$ and $\mathrm{CN}$ and $\mathrm{CCl}$ may be the main ones in the VDC-AN/PMMA blends. One point that should be emphasized is that the chemical environments or electron density of $\mathrm{C}-\mathrm{Cl}$ group in VDC-AN is quite different from those of the $\mathrm{C}-\mathrm{Cl}$ group in homopolymer PVDC. It is this chemical environment difference that makes the miscibility difference between either VDC-AN/PMMA and PVDC/PMMA or VDCAN/PMMA and PAN/PMMA.

To summarize, PMMA and VDC-AN are miscible on a molecular level, due to strong intermolecular interactions between them. The main ones may be dipole-dipole interactions between $\mathrm{C}-\mathrm{O}$ and $\mathrm{C}-\mathrm{Cl}$ groups, and interpolymer hydrogen bondings between $\mathrm{COOCH}_{3}$ and $\mathrm{CN}$ and $\mathrm{CCl}$. There are at least two kinds of $-\mathrm{CCl}_{2}-$ groups with distinct different chemical environments in the VDC-AN copolymer. It is also pointed out that the molecular sequence distribution in a copolymer will have effect on the miscibility of homopolymer/copolymer blends.

Acknowledgments. The authors are grateful to the financial support granted by The National Key Projects for Fundamental Research "Macromolecular Condensed State," The State Science and Technology Commission of China, and the Laboratory of Magnetic Resonance and Atomic and Molecular Physics, Wuhan Institute of Physics, Chinese Academy of Sciences.

\section{REFERENCES}

1. H. Feng, Z. Feng, and L. Shen, submitted to Polym. J.

2. H. Feng, L. Shen, and Z. Feng, Eur. Polym. J., 31, 243 (1995).

3. H. Feng, Z. Feng, and L. Shen, submitted to Polym. J.

4. D. A. Torchia, J. Magn. Reson., 30, 613 (1978).

5. E. O. Stejskal, J. Schaefer, M. D. Sefcik, and R. A. Mckay, Macromolecules, 14, 275 (1981).

6. T. G. Fox, Bull. Am. Phys. Soc., 1, 123 (1956).

7. S. P. Ting, E. M. Pearce, and T. K. Kwei, J. Polym Sci., Polym. Lett. Ed., 18, 201 (1980).

8. L. M. Robeson and A. B. Furtek, J. Appl. Polym. Sci., 23, 645 (1979).

9. M. S. Wu, P. C. Painter, and M. M. Coleman, J. Polym. Sci., Polym. Phys. Ed., 18, 111 (1980).

10. D. F. Varnell, J. P. Runt, and M. M. Coleman, Polymer, 24, 37 (1983). 